\title{
Overlooked Management and Risk Factors for Anemia in Patients with Intestinal Behçet's Disease in Actual Clinical Practice
}

\author{
Bun Kim, Soo Jung Park, Sung Pil Hong, Jae Hee Cheon, Tae II Kim, and Won Ho Kim \\ Department of Internal Medicine and Institute of Gastroenterology, Yonsei University College of Medicine, Seoul, Korea
}

\begin{abstract}
Background/Aims: Anemia in patients with inflammatory bowel disease significantly affects the quality of life. The aim of this study was to investigate the frequency of and risk factors for anemia and to describe the management of anemia in patients with intestinal Behçet's disease (BD) in actual clinical practice. Methods: We included 64 patients with intestinal BD who visited the outpatient clinic of a tertiary referral center in June 2011 and had available laboratory data for the subsequent 6 months. Results: Anemia was detected in 26 patients (40.6\%). After 6 months, anemia was still present in 14 of these patients (53.8\%). The cause of anemia was investigated in eight patients (30.8\%), and oral iron supplementation was prescribed to four patients (15.4\%). Of these four patients, two (50\%) recovered completely within 6 months. Anemia was associated with a high Disease Activity Index for Intestinal Behçet's Disease (DAIBD, $p=0.024$ ), erythrocyte sedimentation rate $(p=0.003)$, and C-reactive protein $(p=0.049)$ in univariate analysis. In multivariate analysis, the factor predictive for anemia in patients with intestinal BD was a higher DAIBD ( $\geq 40$; odds ratio, 4.08 ; $95 \%$ confidence interval, 1.21 to $13.71 ; p=0.023)$. Conclusions: Although anemia is common in intestinal BD patients, its clinical importance is overlooked in daily practice. Moderate to severe disease activity is predictive of anemia. (Gut Liver 2015;9:750-755)
\end{abstract}

Key Words: Intestinal Behcet's disease; Anemia; Frequency; Risk factors

\section{INTRODUCTION}

Behçet's disease (BD), which can cause chronic gastrointestinal (GI) inflammation, is a chronically relapsing multisystem vasculitis, characterized by recurrent oral and genital ulcers, ocular lesions, skin manifestations, arthritis, and vascular, neurologic, and intestinal involvements. ${ }^{1}$ Because GI involvement can cause severe morbidity and mortality, BD is designated "intestinal BD" if GI symptoms predominate and typical ulcerative GI lesions are objectively documented. ${ }^{2-4}$ The frequency of GI involvement ranges from 3\% to 50\% and varies depending on geographic location. ${ }^{5,6}$ The most frequently affected site is the ileocecal region, which presents with symptoms of abdominal pain, diarrhea, and bleeding..$^{7.8}$

The prevalence of anemia in patients with inflammatory bowel disease (IBD) including Crohn's disease (CD) and ulcerative colitis (UC) ranges from 8.8\% to 73.7\%, depending on the patient subpopulation. ${ }^{9-11}$ It has been considered an important factor affecting patient quality of life. ${ }^{11}$ There have been a substantial number of studies on the epidemiology, risk factors and treatments of anemia in $\mathrm{CD}$ and UC. ${ }^{12-14}$

Among IBD patients, iron-deficiency anemia is the most common cause of anemia, and is usually manageable through medication. Iron deficiency is caused by iron malabsorption due to active disease, dietary restrictions, or intestinal bleeding. Moreover, in IBD patients, chronic intestinal inflammation leads to the upregulation of both proinflammatory cytokines (e.g., interleukin [IL]-1 $\beta$, IL-6) and hepcidin, which results in impaired intestinal iron uptake from the gut and impaired iron sequestering in the reticuloendothelial system. ${ }^{15-17}$ In addition, anemia in IBD patients can occur due to treatment. Therapy with sulfasalazine or 5-aminosalicylic acid has been related to a minor degree of hemolysis or aplasia. ${ }^{18}$ Moreover, both 6-mercaptopurine and azathioprine have a direct myelosuppressive effect. ${ }^{19}$ In addition to these possible causes of anemia in IBD, BD, as a type of vasculiits, has the characteristic that reactive oxygen species are produced endogenously at sites of endothelial inflammation by activated leukocytes and it could cause anemia. ${ }^{20}$

Unlike CD and UC, there have been no study on anemia in

Correspondence to: Soo Jung Park

Department of Internal Medicine, Yonsei University College of Medicine, 50-1 Yonsei-ro, Seodaemun-gu, Seoul 03722, Korea

Tel: +82-2-2228-1963, Fax: +82-2-365-2125, E-mail: sjpark@yuhs.ac

Received on May 23, 2014. Revised on October 1, 2014. Accepted on October 14, 2014. Published online May 13, 2015

pISSN 1976-2283 eISSN 2005-1212 http://dx.doi.org/10.5009/gnl14193

(a) This is an Open Access article distributed under the terms of the Creative Commons Attribution Non-Commercial License (http://creativecommons.org/licenses/by-nc/4.0) which permits unrestricted non-commercial use, distribution, and reproduction in any medium, provided the original work is properly cited. 
patients with intestinal BD; therefore, in this study, we sought to establish the frequency of anemia and describe its management in patients with intestinal BD in actual clinical practice.

\section{MATERIALS AND METHODS}

\section{Study design and patients}

A cross-sectional study was performed based on well-organized electronic medical records. We included 77 patients with intestinal BD who had attended the outpatient clinic of a tertiary referral medical center between June 1, 2011 and June 30, 2011. Among them, we excluded 13 patients based on presence of hematologic malignancy or other severe comorbidities, or loss to 6-month follow-up to investigate not only the causes of anemia, but also treatment agents and the results of treatments after 6 months in these patients (three with myelodysplastic syndrome [MDS]; one each with aplastic syndrome [AA], liver cirrhosis, heart failure with valvular heart disease, and accompanied malignancy; six lost to follow-up).

We collected baseline data for clinical and endoscopic characteristics, comorbidities, gastrointestinal surgical history, family history, extraintestinal manifestations, Disease Activity Index for Intestinal Behçet's Disease (DAIBD) ${ }^{21}$ at time of enrollment (June 2011), and any treatment for intestinal BD and anemia. Laboratory data was obtained at baseline and 6 months later, and included white blood cell count, hemoglobin, hematocrit, platelet, mean cell volume, mean corpuscular hemoglobin concentration (MCHC), red cell distribution width (RDW), albumin, erythrocyte sedimentation rate (ESR), and C-reactive protein (CRP). To investigate the type of anemia, serum iron, total iron binding capacity, transferrin saturation (TSAT), vitamin $\mathrm{B}_{12}$, folate and reticulocyte count were obtained at time of enrollment. At 6-month follow-up, hemoglobin levels of all patients were assessed. We chose the 6-month follow-up interval to evaluate the improvement of anemia because the hemoglobin level usually returns to normal by 6 to 8 weeks after taking oral iron.

We used DAIBD to evaluate disease activity in patients with intestinal BD. DAIBD is comprised of the following eight variables: general well-being, fever, extra-intestinal manifestations, abdominal pain, abdominal masses, intestinal complications, and number of liquid stools in 1 week. The DAIBD was used to classify disease into quiescent $(\leq 19)$, mild (20-39), moderate (40-74), or severe $(\geq 75)$ categories. ${ }^{21}$

\section{Definitions of anemia}

Anemia was defined according to the World Health Organization criteria: in men as hemoglobin $<13 \mathrm{~g} / \mathrm{dL}$ and in nonpregnant women as hemoglobin $<12 \mathrm{~g} / \mathrm{dL}$. Iron deficiency anemia (IDA) was defined as a ferritin $<30 \mu \mathrm{g} / \mathrm{L}$ when the corresponding CRP was $<10 \mathrm{mg} / \mathrm{L}$, or a ferritin $<100 \mathrm{ng} / \mathrm{mL}$ when the CRP $>10 \mathrm{mg} / \mathrm{L}$ and/or TSAT $<16 \% .^{22}$ Anemia of chronic disease (ACD) was defined as anemia in the presence of a CRP-adjusted, nor- mal, or increased serum ferritin and/or a low plasma iron and iron binding capacity. ${ }^{23}$ Vitamin $\mathrm{B}_{12}$ deficiency was defined as serum vitamin $B_{12}<180 \mathrm{pg} / \mathrm{mL}$, and folate deficiency as serum folate $<2.34 \mathrm{ng} / \mathrm{mL}$.

\section{Statistical analysis}

Continuous variables were expressed as the mean \pm standard deviation. Baseline characteristics of the nonanemia and anemia groups were compared using a Student t-test for continuous variables and a chi-square test (or Fisher exact test) for categorical variables. In multivariate analysis, logistic regression analysis was used to analyze associative factors of anemia in intestinal BD. Age, sex and the variables for which $\mathrm{p}<0.1$ in univariate analysis except laboratory data were included in multivariate analysis.

Results were considered statistically significant when $\mathrm{p}<0.05$. All statistical analyses were performed using SPSS version 18.0 (SPSS Inc., Chicago, IL, USA).

\section{RESULTS}

\section{Patient characteristics}

From June 1, 2011 to June 30, 2011, a total of 64 patients with intestinal BD enrolled in our study. The baseline characteristics at diagnosis are summarized in Table 1 . The mean age was $46.12 \pm 12.40$ years, and 31.3\% were male. Among these 64 patients, anemia was detected in 26 patients (40.6\%). Twentythree patients (35.9\%) underwent more than one gastrointestinal surgery, including ileocecectomy (13) and right hemicolectomy (9). The mean DAIBD value was $37.73 \pm 32.39$ in June 2011; based on DAIBD, eight patients had severe, 22 had moderate, nine had mild, and 25 had quiescent disease in June 2011. In terms of laboratory data, the mean values of ESR, CRP, and hemoglobin level were $32.27 \pm 27.35 \mathrm{~mm} / \mathrm{hr}, 11.19 \pm 21.16 \mathrm{mg} / \mathrm{L}$, and $12.52 \pm 1.83 \mathrm{mg} / \mathrm{dL}$, respectively.

The cause of anemia was investigated in eight of 26 patients with anemia (one with IDA, two with ACD, four with combined type of IDA and ACD, and the other one with undetermined type); oral ferrous medication was prescribed to four patients. There was no patient who was given intravenous iron and/or erythropoietin (EPO) in this study (Table 1).

\section{Comparison of baseline characteristics with regard to anemia}

The patients were divided into two groups by blood hemoglobin level: those without $(n=38)$ and those with anemia $(n=26)$. A comparison of baseline characteristics is presented in Table 2. Most baseline characteristics, including age, sex, disease duration, type and frequency of gastrointestinal operation and medication for BD were not significantly different between the two groups. However, the number of patients with moderate to severe disease activity in DAIBD was significantly greater in 
Table 1. Baseline Characteristics of Patients with Intestinal Behçet's Disease $(n=64)$

\begin{tabular}{|c|c|}
\hline Characteristic & Value \\
\hline Age, yr & $46.12 \pm 12.4$ \\
\hline Sex, male/female & $20(31.3) / 44(68.8)$ \\
\hline Duration of intestinal BD, mo & $80.03 \pm 61.84$ \\
\hline GI operation & $23(35.9)$ \\
\hline No. of GI operations & $0.64 \pm 21.96$ \\
\hline \multicolumn{2}{|c|}{ Type of GI operation (duplicates allowed) } \\
\hline Appendectomy & $6(9.4)$ \\
\hline Small bowel resection & $5(7.8)$ \\
\hline Right hemicolectomy & $9(14.1)$ \\
\hline Ileocecectomy & $13(20.3)$ \\
\hline Anal fistulectomy & $2(3.1)$ \\
\hline DAIBD & $37.73 \pm 32.39$ \\
\hline Quiescent-mild (0-39) & $34(53.1)$ \\
\hline Moderate-severe $(\geq 40)$ & $30(46.9)$ \\
\hline \multicolumn{2}{|l|}{ Laboratory data } \\
\hline WBC, $/ \mu \mathrm{L}$ & $5,961 \pm 2,737.6$ \\
\hline Hemoglobin, g/dL & $12.52 \pm 1.83$ \\
\hline Hematocrit, \% & $37.96 \pm 4.96$ \\
\hline MCV, fL & $91.63 \pm 9.26$ \\
\hline MCHC, g/dL & $32.62 \pm 1.56$ \\
\hline RDW, \% & $14.57 \pm 2.33$ \\
\hline Platelet, $\times 10^{3} / \mu \mathrm{L}$ & $254.45 \pm 78.88$ \\
\hline Albumin, $\mathrm{g} / \mathrm{dL}$ & $4.20 \pm 0.48$ \\
\hline ESR, mm/hr & $32.27 \pm 27.35$ \\
\hline $\mathrm{CRP}, \mathrm{mg} / \mathrm{L}$ & $11.19 \pm 21.16$ \\
\hline \multicolumn{2}{|c|}{ Intestinal BD medication (duplicates allowed) } \\
\hline Sulfasalazine, mesalazine, 5-ASA & $62(96.9)$ \\
\hline Purine analogue & $22(34.3)$ \\
\hline Anti-TNF- $\alpha$ inhibitor & $1(1.6)$ \\
\hline Corticosteroids & $15(23.4)$ \\
\hline \multicolumn{2}{|l|}{ Laboratory data of anemia } \\
\hline Ferritin $(n=10)$ & $78.24 \pm 119.26$ \\
\hline Serum iron, $\mu \mathrm{g} / \mathrm{dL}$ & $64.9 \pm 39.17$ \\
\hline TIBC, $\mu \mathrm{g} / \mathrm{dL}$ & $293.5 \pm 109.46$ \\
\hline TSAT, $\%$ & $28.8 \pm 26.96$ \\
\hline Vitamin $\mathrm{B}_{12}, \mathrm{pg} / \mathrm{mL}$ & $640.57 \pm 376.93$ \\
\hline Folate, $\mathrm{ng} / \mathrm{mL}$ & $9.26 \pm 6.08$ \\
\hline Reticulocyte count, \% & $1.73 \pm 0.75$ \\
\hline \multicolumn{2}{|l|}{ Iron replacement } \\
\hline Oral ferrous & 4 \\
\hline Intravenous & 0 \\
\hline Erythropoietin & 0 \\
\hline Hemoglobin after $6 \mathrm{mo}, \mathrm{g} / \mathrm{dL}$ & $13.03 \pm 1.54$ \\
\hline
\end{tabular}

Data are presented as mean \pm SD or number $(\%)$.

$\mathrm{BD}$, Behçet's disease; GI, gastrointestinal; DAIBD, Disease Activity Index for Intestinal Behçet's Disease; WBC, white blood cell count; $\mathrm{MCV}$, mean cell volume; MCHC, mean corpuscular hemoglobin concentration; RDW, red cell distribution width; ESR, erythrocyte sedimentation rate; CRP, C-reactive protein; 5-ASA, 5-aminosalicylic acid; anti-TNF- $\alpha$, anti-tumor necrosis factor $\alpha$; TIBC, total iron binding capacity; TSAT, transferrin saturation. the anemia group than in the nonanemia group (18/26 [69.2\%] vs $12 / 38$ [31.6\%], $\mathrm{p}=0.003$ ). Also, ESR and CRP, both thought to be associated with disease activity, were significantly higher in the anemia group than in the nonanemia group $(46.15 \pm 34.0$ $\mathrm{mm} / \mathrm{hr}$ vs $22.76 \pm 16.26 \mathrm{~mm} / \mathrm{hr}, \mathrm{p}=0.003 ; 17.31 \pm 21.98 \mathrm{mg} / \mathrm{L}$ vs $6.41 \pm 19.99 \mathrm{mg} / \mathrm{L}, \mathrm{p}=0.049$, respectively). The anemia group had higher mean values of RDW (15.94\% $0 \pm 2.70 \%$ vs $13.62 \% \pm 1.43 \%$, $\mathrm{p}<0.001)$ and platelet count $\left(288.08 \pm 91.82 \times 10^{3} / \mu \mathrm{L}\right.$ vs $231.45 \pm$ $\left.59.66 \times 10^{3} / \mu \mathrm{L}, \mathrm{p}<0.001\right)$ than the nonanemia group. Hemoglobin $(10.85 \pm 1.08 \mathrm{~g} / \mathrm{dL}$ vs $13.67 \pm 1.26 \mathrm{~g} / \mathrm{dL}, \mathrm{p}<0.001)$, hematocrit (33.49\% $\pm 3.25 \%$ vs $41.02 \% \pm 3.32 \%, \mathrm{p}<0.001)$, MCHC $(31.95 \pm 1.58$ $\mathrm{g} / \mathrm{dL}$ vs $33.62 \pm 1.40 \mathrm{~g} / \mathrm{dL}, \mathrm{p}=0.004)$, and albumin $(3.91 \pm 0.57 \mathrm{~g} / \mathrm{dL}$ vs $4.39 \pm 0.29 \mathrm{~g} / \mathrm{dL}, \mathrm{p}<0.001$ ) were lower in the anemia group.

The cause of anemia was investigated in only eight patients $(30.8 \%)$ of the 26 with anemia, and oral ferrous medicines prescribed to four (50\%); these four were prescribed ferrous sulfate $256 \mathrm{mg}$ once or twice daily, and two (50\%) were able to recover normal hemoglobin levels within 6 months. Overall hemoglobin levels in all patients after 6 months were lower $(11.99 \pm 1.12$ vs $13.75 \pm 1.38, \mathrm{p}<0.001)$, and anemia (14/26 [53.8\%] vs $2 / 38$ [5.3\%], $\mathrm{p}<0.001$ ) was more frequent in the initial anemia group (Table 2).

\section{Factors predictive of anemia in intestinal BD according to multivariate analysis}

In multivariate analysis adjusted for age, sex, number of GI operation, DAIBD and corticosteroids use, the independent factor predictive of anemia in patients with intestinal BD was moderate to severe DAIBD (odds ratio, 4.08; 95\% confidence interval, 1.21 to $13.71 ; \mathrm{p}=0.023)$. However, the number of previous gastrointestinal operation and corticosteroids use were not independent factors relating anemia to IBD (Table 3).

\section{DISCUSSION}

In the present study, we found the frequency, short-term prognosis, and predictive factors of anemia in intestinal BD patients for the first time. Anemia in patients with intestinal BD was detected as high as $40.6 \%$ in this study. Moreover, anemia was meaningfully associated with disease activity of intestinal BD.

Similar to anemia in patients with IBD, anemia in patients with intestinal BD can occur due to chronic disease, iron deficiency, vitamin deficiency and treatment itself such as sulfasalazine, 5-aminosalicylic acid, and azathioprine. Despite, in this study, the number of patients who were surveyed the cause of anemia was small $(8 / 26,30.77 \%)$ in the anemia group, seven out of eight were associated with IDA and/or ACD. This finding was accordance with the result of a previous study in patients with IBD which showed that the main causes of anemia in IBD were mostly IDA, ACD, and a combination of both. ${ }^{9}$

In addition, our study showed that the anemia group had higher platelet count than the nonanemia group and it also 
Table 2. Comparisons of Baseline Characteristics with Regard to Anemia

\begin{tabular}{|c|c|c|c|}
\hline Characteristic & Nonanemia group $(\mathrm{n}=380)$ & Anemia group $(\mathrm{n}=26)$ & $\mathrm{p}$-value \\
\hline Age, yr & $44.34 \pm 12.27$ & $48.73 \pm 12.36$ & 0.166 \\
\hline Male sex & $11(28.9)$ & $9(34.6)$ & 0.783 \\
\hline \multicolumn{4}{|l|}{ Medication } \\
\hline NSAIDs & $14(36.8)$ & $11(42.3)$ & 0.660 \\
\hline Antiplatelet drug & $2(5.3)$ & $1(3.8)$ & 0.641 \\
\hline Duration of intestinal BD, mo & $77.82 \pm 58.18$ & $83.27 \pm 67.89$ & 0.732 \\
\hline GI operation & $11(28.9)$ & $12(46.2)$ & 0.159 \\
\hline No. of GI operations & $0.46 \pm 0.76$ & $0.96 \pm 1.71$ & 0.090 \\
\hline $0-1$ & $34(61.8)$ & $21(38.2)$ & 0.467 \\
\hline$\geq 2$ & $4(44.4)$ & $5(55.6)$ & \\
\hline \multicolumn{4}{|c|}{ Type of GI operation (duplicates allowed) } \\
\hline Appendectomy & $2(5.3)$ & $4(66.7)$ & 0.213 \\
\hline Small bowel resection & $3(7.9)$ & $2(7.7)$ & $>0.999$ \\
\hline Right hemicolectomy & $3(7.9)$ & $6(23.1)$ & 0.142 \\
\hline Ileocecectomy & $6(15.8)$ & $7(26.9)$ & 0.277 \\
\hline Anal fistulectomy & $1(2.6)$ & $1(3.8)$ & $>0.999$ \\
\hline DAIBD & $30.26 \pm 30.36$ & $48.65 \pm 32.73$ & 0.024 \\
\hline Quiescent-mild (0-39) & $26(68.4)$ & $8(30.8)$ & 0.003 \\
\hline Moderate-severe $(\geq 40)$ & $12(31.6)$ & $18(69.2)$ & \\
\hline \multicolumn{4}{|l|}{ Laboratory data } \\
\hline $\mathrm{WBC}, / \mu \mathrm{L}$ & $5,424.47 \pm 1,998.12$ & $6,745.38 \pm 3,449.61$ & 0.087 \\
\hline Hemoglobin, g/dL & $13.67 \pm 1.26$ & $10.85 \pm 1.08$ & $<0.001$ \\
\hline Hematocrit, \% & $41.02 \pm 3.32$ & $33.49 \pm 3.25$ & $<0.001$ \\
\hline MCV, fL & $91.26 \pm 7.09$ & $92.16 \pm 11.88$ & 0.732 \\
\hline MCHC, g/dL & $33.62 \pm 1.40$ & $31.95 \pm 1.58$ & 0.004 \\
\hline RDW, \% & $13.62 \pm 1.43$ & $15.94 \pm 2.70$ & $<0.001$ \\
\hline Platelet, $\times 10^{3} / \mu \mathrm{L}$ & $231.45 \pm 59.66$ & $288.08 \pm 91.82$ & 0.009 \\
\hline Albumin, g/dL & $4.39 \pm 0.29$ & $3.91 \pm 0.57$ & $<0.001$ \\
\hline $\mathrm{ESR}, \mathrm{mm} / \mathrm{hr}$ & $22.76 \pm 16.26$ & $46.15 \pm 34.0$ & 0.003 \\
\hline $\mathrm{CRP}, \mathrm{mg} / \mathrm{L}$ & $6.41 \pm 19.99$ & $17.31 \pm 21.98$ & 0.049 \\
\hline \multicolumn{4}{|c|}{ Intestinal BD medication (duplicates allowed) } \\
\hline Sulfasalazine, mesalazine, 5-ASA & $36(94.7)$ & $26(100)$ & 0.510 \\
\hline Purine analogue & $13(34.2)$ & $9(34.6)$ & 0.973 \\
\hline Anti-TNF- $\alpha$ inhibitor & 0 & $1(3.8)$ & 0.406 \\
\hline Corticosteroids & $6(15.8)$ & $9(34.6)$ & 0.081 \\
\hline Anemia laboratory data & $(\mathrm{n}=2)$ & $(\mathrm{n}=8)$ & \\
\hline Ferritin, ng/mL & $58.10 \pm 38.33$ & $83.28 \pm 133.91$ & 0.807 \\
\hline Serum iron, $\mu \mathrm{g} / \mathrm{dL}$ & $49.50 \pm 12.02$ & $68.75 \pm 43.21$ & 0.566 \\
\hline TIBC, $\mu \mathrm{g} / \mathrm{dL}$ & $258.50 \pm 34.65$ & $302.25 \pm 121.64$ & 0.642 \\
\hline TSAT, $\%$ & $19.00 \pm 1.41$ & $31.25 \pm 30.0$ & 0.596 \\
\hline Reticulocyte count, \% & $\begin{array}{c}1.86 \pm 1.0 \\
(n=1)\end{array}$ & $\begin{array}{c}1.70 \pm 0.76 \\
(\mathrm{n}=6)\end{array}$ & 0.807 \\
\hline Vitamin $\mathrm{B}_{12}, \mathrm{pg} / \mathrm{mL}$ & 808.0 & $612.67 \pm 404.91$ & 0.674 \\
\hline Folate, $\mathrm{ng} / \mathrm{mL}$ & 3.02 & $10.30 \pm 5.94$ & 0.308 \\
\hline Iron replacement & & & 0.024 \\
\hline Oral ferrous & 0 & $4(15.4)$ & \\
\hline Intravenous & 0 & 0 & \\
\hline Erythropoietin & 0 & 0 & \\
\hline Hemoglobin after $6 \mathrm{mo}, \mathrm{g} / \mathrm{dL}$ & $13.75 \pm 1.38$ & $11.99 \pm 1.12$ & $<0.001$ \\
\hline Anemia after 6 mo & $2(5.3)$ & 14 (53.8) & $<0.001$ \\
\hline
\end{tabular}

Data are presented as mean \pm SD or number $(\%)$.

NSAIDs, nonsteroidal anti-inflammatory drugs; BD, Behçet's disease; GI, gastrointestinal; DAIBD, Disease Activity Index for Intestinal Behçet's Disease; WBC, white blood cell count; MCV, mean cell volume; MCHC, mean corpuscular hemoglobin concentration; RDW, red cell distribution width; ESR, erythrocyte sedimentation rate; CRP, C-reactive protein; 5-ASA, 5-aminosalicylic acid; anti-TNF- $\alpha$, anti-tumor necrosis factor $\alpha$; TIBC, total iron binding capacity; TSAT, transferrin saturation. 
Table 3. Factors Predictive of Anemia in Intestinal Behçet's Disease according to the Multivariate Analysis

\begin{tabular}{llc}
\hline \multicolumn{1}{c}{ Factor } & \multicolumn{1}{c}{ OR $(95 \% \mathrm{CI})$} & $\mathrm{p}$-value \\
\hline Age, yr & $1.04(0.99-1.09)$ & 0.099 \\
Male sex & $0.94(0.28-3.23)$ & 0.925 \\
No. of GI operations & $1.43(0.76-2.70)$ & 0.271 \\
DAIBD ( $\geq 40$, moderate-severe) & $4.08(1.21-13.71)$ & 0.023 \\
Intestinal BD medication & & \\
Corticosteroids use & $1.58(0.40-6.23)$ & 0.512 \\
\hline
\end{tabular}

OR, odds ratio; CI, confidence interval; GI, gastrointestinal; DAIBD, Disease Activity Index for Intestinal Behçet's Disease; BD, Behçet's disease.

accordance with previous studies of IBD. Several studies suggest that platelets are involved in the pathogenesis of IBD and increased platelet count has been associated with disease activity in IBD. ${ }^{24-27}$ Moreover, reactive thrombocytosis has been associated in adults with iron deficiency anemia, inflammatory conditions. ${ }^{28}$ As a result, both inflammation and iron deficiency predisposes patients with $\mathrm{BD}$ as well as UC and CD to develop thrombocytosis.

Interestingly, BD, which is predominantly associated with $\mathrm{MDS}^{29}$ is highly relevant to anemia itself. In such cases those are associated with MDS, patients with BD demonstrate more frequent gut involvement, and were associated with trisomy 8 in their bone marrow. ${ }^{30,31}$ Besides MDS, there may also be an association between BD and bone marrow failure, such as in AA. Consistent with these findings, there were three patients (3/87, $3.45 \%)$ with MDS and one patient (1/87, 1.15\%) with AA who were initially excluded in this study.

Furthermore, despite the exclusion of patients with bone marrow failure-related anemia, this study showed that the frequency of anemia in intestinal BD patients (40.6\%) remained as high as that of patients with $\mathrm{CD}$ and UC. ${ }^{9-11}$

The ultimate therapeutic goal for intestinal BD patients with anemia is improvement in quality of life; however, in this study, the only objective measures we can gather are changes in laboratory data, including hemoglobin concentrations. In anemic cancer patients, improvements in quality of life were reported beginning at hemoglobin levels of up to $14 \mathrm{~g} / \mathrm{dL}^{32}$ Since BD patients are younger, on average, than cancer patients, they may experience higher physical and cognitive demands; thus, normalization of hemoglobin levels (12.0 g/dL in women and 13.0 $\mathrm{g} / \mathrm{dL}$ in men) in patients with intestinal BD should be considered as for the goal of treatment of anemia in CD and UC patients.

According to multivariate analysis, intestinal BD patients with moderate to severe DAIBD are likely to have anemia. This is a similar finding with IBD patients. In IBD patients, previous studies showed that the higher disease activity was associated with lower hemoglobin and hematocrit level and this phenomenon was explained as inflammation inhibits iron absorption and links to abnormal iron homeostasis. ${ }^{13,33}$ Physicians should evaluate the causes and types of anemia, and aggressively manage the intestinal BD patients with anemia using intravenous iron and/or EPO in order to prevent the increase of frequency of anemia and identify malignant conditions such as MDS or AA.

There were several limitations in our study. First, it was a retrospective, cross-sectional, case-control study that was based on medical record review. Nevertheless, we sought to identify predictive factors of anemia by analyzing a well-organized, computer-based medical database. Secondly, data were collected from a single hospital that was part of a tertiary referral center. This might cause our patient group to differ from the general population of Koreans with BD. Due to its rarity and challenging diagnosis, however, most BD patients were managed in tertiary university hospitals rather than primary or secondary medical centers in Korea, and our medical center follows up the largest number of the patients with intestinal BD in Korea. As such, the patient group in this study could show less bias, though patients were recruited from a single tertiary university hospital.

In conclusion, the frequency of anemia in patients with intestinal BD was as high as that of patients with CD and UC. However, the importance of anemia in intestinal BD patients is still overlooked in clinical practice. Therefore, we suggest that physicians pay particular attention to anemia in patients with intestinal $\mathrm{BD}$, in order to improve patient quality of life and monitor for serious underlying problems, such as MDS and AA.

\section{CONFLICTS OF INTEREST}

No potential conflict of interest relevant to this article was reported.

\section{REFERENCES}

1. Sakane T, Takeno M, Suzuki N, Inaba G. Behçet’s disease. N Engl J Med 1999;341:1284-1291.

2. Yang SK. Intestinal Behçet's disease. Intest Res 2005;3:1-10.

3. Bayraktar Y, Ozaslan E, Van Thiel DH. Gastrointestinal manifestations of Behçet’s disease. J Clin Gastroenterol 2000;30:144-154.

4. Jung YS, Park DI, Moon CM, et al. Radiation exposure from abdominal imaging studies in patients with intestinal Behçet disease. Gut Liver 2014;8:380-387.

5. Shimizu T, Ehrlich GE, Inaba G, Hayashi K. Behçet disease (Behçet syndrome). Semin Arthritis Rheum 1979;8:223-260.

6. Gürler A, Boyvat A, Türsen U. Clinical manifestations of Behçet's disease: an analysis of 2147 patients. Yonsei Med J 1997;38:423427.

7. Lee CR, Kim WH, Cho YS, et al. Colonoscopic findings in intestinal Behçet's disease. Inflamm Bowel Dis 2001;7:243-249.

8. Lee HW, Kim WH, Cheon JH. The medical treatments of intestinal Behçet's disease: an update. Intest Res 2013;11:155-160.

9. Gasche C, Lomer MC, Cavill I, Weiss G. Iron, anaemia, and inflam- 
matory bowel diseases. Gut 2004;53:1190-1197.

10. Kulnigg S, Gasche C. Systematic review: managing anaemia in Crohn's disease. Aliment Pharmacol Ther 2006;24:1507-1523.

11. Wilson A, Reyes E, Ofman J. Prevalence and outcomes of anemia in inflammatory bowel disease: a systematic review of the literature. Am J Med 2004;116 Suppl 7A:44S-49S.

12. Rizvi S, Schoen RE. Supplementation with oral vs. intravenous iron for anemia with IBD or gastrointestinal bleeding: is oral iron getting a bad rap? Am J Gastroenterol 2011;106:1872-1879.

13. Cakal B, Akoz AG, Ustundag Y, Yalinkilic M, Ulker A, Ankarali H. Red cell distribution width for assessment of activity of inflammatory bowel disease. Dig Dis Sci 2009;54:842-847.

14. Bergamaschi G, Di Sabatino A, Albertini R, et al. Prevalence and pathogenesis of anemia in inflammatory bowel disease: influence of anti-tumor necrosis factor-alpha treatment. Haematologica 2010;95:199-205.

15. Ganz T. Hepcidin, a key regulator of iron metabolism and mediator of anemia of inflammation. Blood 2003;102:783-788.

16. Nemeth E, Rivera S, Gabayan V, et al. IL-6 mediates hypoferremia of inflammation by inducing the synthesis of the iron regulatory hormone hepcidin. J Clin Invest 2004;113:1271-1276.

17. Nemeth E, Tuttle MS, Powelson J, et al. Hepcidin regulates cellular iron efflux by binding to ferroportin and inducing its internalization. Science 2004;306:2090-2093.

18. Bernstein CN, Artinian L, Anton PA, Shanahan F. Low-dose 6-mercaptopurine in inflammatory bowel disease is associated with minimal hematologic toxicity. Dig Dis Sci 1994;39:16381641.

19. Black AJ, McLeod HL, Capell HA, et al. Thiopurine methyltransferase genotype predicts therapy-limiting severe toxicity from azathioprine. Ann Intern Med 1998;129:716-718.

20. Köse K, Yazici C, Cambay N, Aşcioğlu 0, Doğan P. Lipid peroxidation and erythrocyte antioxidant enzymes in patients with Behçet’s disease. Tohoku J Exp Med 2002;197:9-16.

21. Cheon JH, Han DS, Park JY, et al. Development, validation, and responsiveness of a novel disease activity index for intestinal Behçet's disease. Inflamm Bowel Dis 2011;17:605-613.

22. Gasche C, Berstad A, Befrits R, et al. Guidelines on the diagnosis and management of iron deficiency and anemia in inflammatory bowel diseases. Inflamm Bowel Dis 2007;13:1545-1553.

23. Cartwright GE, Lee GR. The anaemia of chronic disorders. Br J Haematol 1971;21:147-152.

24. Harries AD, Fitzsimons E, Fifield R, Dew MJ, Rhoades J. Platelet count: a simple measure of activity in Crohn's disease. Br Med J (Clin Res Ed) 1983;286:1476.

25. Morowitz DA, Allen LW, Kirsner JB. Thrombocytosis in chronic inflammatory bowel disease. Ann Intern Med 1968;68:1013-1021.

26. Talstad I, Rootwelt K, Gjone E. Thrombocytosis in ulcerative colitis and Crohn's disease. Scand J Gastroenterol 1973;8:135-138.

27. van Wersch JW, Houben P, Rijken J. Platelet count, platelet function, coagulation activity and fibrinolysis in the acute phase of inflammatory bowel disease. J Clin Chem Clin Biochem 1990;28:513-517.

28. Griesshammer M, Bangerter M, Sauer T, Wennauer R, Bergmann L, Heimpel H. Aetiology and clinical significance of thrombocytosis: analysis of 732 patients with an elevated platelet count. J Intern Med 1999;245:295-300.

29. Tada Y, Koarada S, Haruta Y, Mitamura M, Ohta A, Nagasawa K. The association of Behçet's disease with myelodysplastic syndrome in Japan: a review of the literature. Clin Exp Rheumatol 2006;24(5 Suppl 42):S115-S119.

30. Kawabata H, Sawaki T, Kawanami T, et al. Myelodysplastic syndrome complicated with inflammatory intestinal ulcers: significance of trisomy 8. Intern Med 2006;45:1309-1314.

31. Ahn JK, Cha HS, Koh EM, et al. Behcet's disease associated with bone marrow failure in Korean patients: clinical characteristics and the association of intestinal ulceration and trisomy 8. Rheumatology (Oxford) 2008;47:1228-1230.

32. Crawford J, Cella D, Cleeland CS, et al. Relationship between changes in hemoglobin level and quality of life during chemotherapy in anemic cancer patients receiving epoetin alfa therapy. Cancer 2002;95:888-895.

33. Song CS, Park DI, Yoon MY, et al. Association between red cell distribution width and disease activity in patients with inflammatory bowel disease. Dig Dis Sci 2012;57:1033-1038. 